\title{
Learner Inclinations to Study Computer Science or Information Systems at Tertiary Level
}

\author{
C Jacobs, DA Sewry \\ Department of Information Systems, Rhodes University, South Africa
}

\begin{abstract}
After the so-called "dot-com crash" of the Internet in the early 2000s, tertiary level student enrolments in IT-related subjects began to experience a significant decline both in international countries and South Africa. The paper replicates research done in the Western Cape, South Africa, by Seymour et al. (2005) [20], in which grade 12 learner inclinations to study Computer Science (CS) and Information Systems (IS) at tertiary level were analysed and underlying factors affecting their interest in the subjects were determined. The study analyses the "misguided" perceptions that learners and students have of these subjects; the implications of the decline in enrolments on students, educational sectors and industry; and determines a set of underlying factors that influence learners in their attitudes toward further degrees in IT, starting from the secondary level of education.

The research compares South African Eastern Cape learner perceptions with those from the Western Cape study and establishes three to four years later, that the reasons behind the decline in IT enrolments are still influenced by an underlying demographic and digital divide.
\end{abstract}

CATEGORIES AND SUBJECT DESCRIPTORS:

K.3.2.

GENERAL TERMS:

Enrolment, ICT-related subjects

ADDITIONAL KEY WORDS AND PHRASES:

Education, Learning

\section{INTRODUCTION}

The research analyses factors that may influence Grahamstown learners in pursuing degrees in Computer Science (CS) or Information Systems (IS) by replicating a similar study conducted in the Western Cape [20].

In a world where technology is being increasingly integrated into people's daily lives, it is surprising to find that students are losing interest in IT-related subjects [6]. Since the dot-com crash, Computer Science and other related subject enrolments have declined and this has had a profound impact on the ICT industry and educational sectors [14]. Seymour, et al. [20] state that South African is experiencing an increased demand for IT graduates and since schools have limited access to computer facilities, learners appear less inclined to take IT-related subjects. The concern that these declines and lack of interest interest pose is whether or not the trend will continue and cause problems in employment and educational sectors.

The responsibility of the status of CS or related subject enrolments lies with the school education system [20]. A shortage of qualified science and technology educators are evident at the primary, secondary and tertiary levels [5]. Patterson [18] suggests that a lack of funding and teacher training hinders the adoption of a new curriculum to interest students in the field of IT. Others, however, deduce that the responsibility lies with the general public and their misconceptions surrounding the dot-com bubble burst in 2000-2002; likely employment opportunities; and a lack of understanding about the IT field in general [22].

The paper commences with a brief review of the literature, which includes the general trend of IT enrolments, reasons for the decline, implications thereof, the differences between CS and IS and the attitudes of learners to further education in these fields. A survey with a set of hypotheses adapted from Seymour et al.'s [20] research is described and its administration to a number of Grade 12 learners in Grahamstown detailed. After a discussion of findings, results are compared to those of Seymour et al. [20] and conclusions are drawn.

\section{LITERATURE REVIEW}

\subsection{Trend}

The 1980's saw an increasingly large proportion of students moving into the technology field due to the shift from an industrial economy to an information-based economy [5]. A general decline in the field followed the shift, the impact of which was mitigated by high salaries and possibilities of gaining extreme wealth through working for 
start-up companies. In the early 2000s, interest in technology reached an all time peak due to the popularity of IT employment and the Internet [18]. Since the dot-com crash, however, Computer Science and other related subjects enrolments have dwindled [14]. The negative impact has been exacerbated through media stories of the "end of IT" [13]. The environment within which computing operates in the $21^{\text {st }}$ century is dramatically different to that of the $60 \mathrm{~s}, 70 \mathrm{~s}, 80 \mathrm{~s}$ and even early $90 \mathrm{~s}$. People are accepting computers as ubiquitous and commoditized [15]. Denning and McGettrick [7] found a $60 \%$ drop in the US and a $43 \%$ drop in the UK of incoming CS students between 2000 and 2004. From a local perspective, the Eastern Cape has the highest number of schools, but the lowest percentage of those who have access to computers, when compared to Gauteng and the Western Cape. A general decline in the pass rate of IT at school is evident during 2004 and 2005 [17]. In addition, Rhodes University experienced an increase in the number of $\mathrm{CS}$ and IS $3^{\text {rd }}$ Year enrolments shortly after the dot-com boom from 2000 to 2003 , followed by a significant decrease in the enrolments of both subjects up to 2008 [21].

\subsection{REASONS FOR THE DECLINE}

It is evident that there are many reasons for the decline in enrolments and public opinion is responsible for most of them. Common misconceptions about the study of CS are that the subject is aimed at intelligent and gifted individuals only; programming in an advanced high-level language is the only career option; and packaged solutions remove the need for a vast army of computer scientists [15]. Most cynics believe that students' interest in IT can be improved by sharp marketing, McBride [15] states that students are not that gullible and that the nature of the problem lies at the roots of IT. Fifty years ago, there was excitement at making a computer perform any task at all, now it seems vastly complex applications for businesses can be developed with a multitude of object-oriented tools without extensive programming knowledge at all. Computer science is said to have lost its "mystique" and the gap between the educational and industrial sectors is growing larger [15].

Other potential causes for the decline in enrolments are found in the educational capacity of schools and universities and how they contribute to the study of CS and other related subjects in IT. Part of the reason for students losing interest is the collective failure of educators, researchers and practitioners to communicate a coherent and convincing narrative about the science of computing and not just the technology [2].

The final contributor to the status of CS enrolments is attributed to industry, where the jobs, careers and futures of every student are held in the balance. The way in which students perceive career prospects is an important consideration when deciding on their field of choice. In the 1980s, there were exaggerated expectations for CS careers, but the hype in moving from that industrial economy to the information-based economy had already generated popularity in the field [5]. However, students do not believe in the job market in computers anymore. They believe that ship has sunk along with the demise of the dot-com hype [11].

\subsection{IMPLICATIONS}

The decline in enrolments for CS throughout the world indicates a profound lack of student interest in IT-related subjects. Lost interest implies fewer enrolments which mean that educational sectors face a lack of demand for their capacity to educate CS professionals. The constantly changing field and economy creates a barricade over the stagnant curriculum, while offshore outsourcing forces jobs out of the country and away from skilled locals [3]. Schools and other educational institutions are not keeping up with the rapidly changing economy as more and more skilled IT professionals are needed. Currently only $20 \%$ of students will earn a four-year degree enabling them to be suitably qualified for the IT industry [23]. South Africa, in particular, faces an alarming ICT skills shortage with the increasing demand far exceeding the country's supply of IT professionals [8].

Most importantly are the flawed and distinctly negative perceptions of CS and computing careers that students have. A major outreach program, with the participation of both industry and academia, will be necessary, particularly before students enter tertiary education. Students need to be exposed to intriguing, innovative and challenging topics that will enhance the learning experience. Additionally, regarding future careers, students should be informed of the skills required, the relatively high salaries, the inevitable growth of the field and its relative importance [5]. The provision of special, limited work permits for foreign graduates of South African universities will help in pooling the available skills in the short to medium term [3]. Dedicated skilled ICT manpower is needed in university departments, as well as expanded partnerships and collaborations between the ICT industry, the government and the universities [3]. The Birchwood Declaration [3] was developed in 2007 as a result of the significant ICT skills gap between educational and industry sectors in South Africa. The document highlights the importance of ICTs within South Africa; the impact of the ICT skills gap on the workforce; and proposes a 5-year intervention will help address the issues of intake, curriculum, graduate production and resource improvement in the ICT sector [3].

\subsection{DIFFERENCE BETWEEN CS/IS}

As the field of Computer Science (CS) evolves at an astonishing pace with new technologies being introduced and existing ones becoming obsolete, the field becomes increasingly difficult to define [1]. It is important to distinguish CS from Information Systems (IS), in order to determine which has a greater effect on the decline in enrolments.

In South African schools, Computer Applications Technology (CAT) and Information Technology (IT) are the IT-related subjects offered from grades 10-12.

CAT is a relatively new subject being taught in South African schools that covers the use of ICTs in an end-user environment to solve problems relating to the processing, presentation and communication of information [9]. IT provides learners with the skills to understand complex principles of the hardware and software of ICTs; the use of digital technology to solve problems; and programming for designing, developing and implementing systems to solve these problems [10]. 
CS taken at tertiary level encompasses a technical framework more akin to IT than CAT taken at secondary level. CS is based on an intensive study of programming, the languages and their implementation [7]. All CS students must learn to integrate theory and practice, to recognize the importance of abstraction and to appreciate the value of good engineering design [1].

Although IS is not directly taught at secondary level, there are certain aspects of CAT and IT that are similar to the IS curriculum taught in tertiary education.

IS is defined as a technology used to support the operation of an organization by concentrating on the organisation's mission and objectives and the application of technology to further these goals [5].

Even though CS has its own stereotypical perceptions, the IS field needs more visibility [12]. In South Africa, it was found that $70 \%$ of learners have heard of CS before, while only $40 \%$ have heard of IS [20]. The relatively new discipline of IS has similar concepts taught in CAT and IT at secondary level, but is not explicitly related to that taught at tertiary level. Learners are thus unaware of the potential offerings of IS as a subject choice.

\subsection{ATTITUDES OF LEARNERS TO FURTHER EDUCATION}

In examining learners' attitudes to IT-related subjects, it is evident that they have high levels of anxiety which prevent them from taking IT. Here, a student's previous experiences with computers affect their attitudes towards future use. Anxiety is found to increase with experience while a positive attitude decreases. Although this implies that only the initial learning curve is steep, it still prevents students from wanting to take the course [4]. Learners are additionally prevented from taking CS at a tertiary level because of their limited academic record in science and mathematics and the fact that technology changes faster than the curriculum [16].

All South African universities require a National Senior Certificate with university exemption for acceptance into any of their courses. Most learners do not have the prerequisites for IT-related subjects in universities and of those who do, only about a third apply for these subjects [19]. It is thus increasingly difficult for students just to gain admission to these courses. Students also have limited knowledge of the field of IS in particular, again preventing them from taking the subject. Students are currently not counselled or informed about the subject, nor are they given the chance to experience the subject and its prospects. An overwhelming lack of interest in technical careers and the impression that the work involved is either too hard or too technical dissuades students from enrolling in these subjects [12]. Increased exposure to the CS and IS fields is necessary to help students see the subjects as integral to a business degree and consider them for a major. Shifting the focus of the IS curriculum to its impact on the organization, treating technology as a tool and downplaying programming may attract more students who want to interact with people, not computers [12].

\section{METHODOLOGY AND SAMPLING}

Existing theories which accurately predict behavior and reality are adapted to the research at hand and tested accordingly in an attempt to formulate a general understanding of enrolments in IT. The Western Cape has almost the highest percentage of computers in schools (second only to Gauteng), while the Eastern Cape has the lowest. The Western Cape also has just short of 1500 schools, while the Eastern Cape has over 6000 schools [17]. Grahamstown in the Eastern Cape boasts a good opportunity to analyse the state of ICT skills and enrolments in schools surrounding Rhodes University and the attitudes of learners to taking IT-related subjects at tertiary level.

Seymour et al., [20] distributed a questionnaire survey to a number of grade 12 learners in the Western Cape to determine their interest in CS and IS. Schools under investigation were classified according to School Type (private or public), School Status (previously advantaged or disadvantaged during the Apartheid era) and School Gender (male, female, or co-educational).

In the questionnaire, the learners were firstly asked to provide their demographic details, including the name of their school, their gender and their race. They were then asked to indicate their first, second and third subject choices for tertiary study, from a list of fourteen options of which two were Computer Science and Information Systems. Interest in CS/IS is confirmed if they chose either of these subjects. Questions relating to the digital divide followed requiring learners to indicate whether or not they had access to computers and the Internet at school and at home. Learners were also asked to indicate on a five-point Likertscale their perceptions about typical CS/IS students at University and general perceptions about the IT job market. Academics at the University of Cape Town also answered these questions and the mean of their answers was taken as the "correct" answer for each statement.

The questionnaire survey [20] is replicated in this study and slightly adjusted to suit a Grahamstown context:

- The Asian race was removed in order to follow current standard demographic practice.

- Journalism was included as a possible subject choice owing to its popularity at Rhodes University.

- Questions relating to computer and Internet access at home were removed and only those with access at school were considered.

- Academics at Rhodes University were required to answer questions relating to perceptions about typical CS/IS students and the IT job market.

\subsection{HYPOTHESES AND QUESTIONNAIRE DESIGN}

The hypotheses used in Seymour et al. [20] are replicated and listed below.

- $\quad \mathbf{H}_{1}$ : Learners attending previously disadvantaged schools are less inclined to study IS or CS than learners attending previously advantaged schools

- $\quad \mathbf{H}_{2}$ : Learners with no access to computers at school are less inclined to study IS or CS than learners with access to computers at school

- $\quad \mathbf{H}_{3}$ : Learners with no access to the Internet at school are less inclined to study IS or CS than learners with access

- $\quad \mathbf{H}_{4}$ : Learners with no access to computers at home are less inclined to study IS or CS than learners with access to computers at home 
- $\quad \mathbf{H}_{5}$ : Learners with no access to the Internet at home are less inclined to study IS or CS than learners with access

- $\quad \mathbf{H}_{\mathbf{6}}$ : Black and Coloured learners are less inclined to study IS or CS than White learners

- $\quad \mathbf{H}_{7}$ : Female learners are less inclined to study CS and IS than male learners

- $\quad \mathbf{H}_{\mathbf{8 A}}$ : Learners who have negative perceptions about an IT starting salary are less inclined to study IS or CS than learners who have positive perceptions

- $\quad \mathbf{H}_{\mathbf{8 B}}$ : Learners who have negative perceptions about the number of IT jobs available are less inclined to study IS or CS than learners who have positive perceptions

- $\quad \mathbf{H}_{\mathbf{8 C}}$ : Learners who have negative perceptions about the IT job market always having jobs are less inclined to study IS or CS than learners who have positive perceptions

- $\quad \mathbf{H}_{\mathbf{9}}$ : Learners do not know what IS as a field of study entails

- $\quad \mathbf{H}_{\mathbf{1 0}}$ : Learners do not know what CS as a field of study entails

In this study, hypotheses $\mathrm{H}_{4}$ and $\mathrm{H}_{5}$ are removed as only computer and Internet access at school are considered in the results $\left(\mathrm{H}_{2}\right.$ and $\left.\mathrm{H}_{3}\right)$.

\subsection{SAMPLING}

The sample in the Western Cape consisted of grade 12 learners (matriculants) from 56 schools. Five hundred and twenty questionnaires were distributed and 497 were used in data analysis.

The sample in the Eastern Cape consisted of grade 12 learners from 11 schools in the greater Grahamstown region. The schools chosen covered a diverse range of previously advantaged and disadvantaged schools, both private and public with an equal number of male and female learners. Figure 1 shows the school status distribution of the schools.

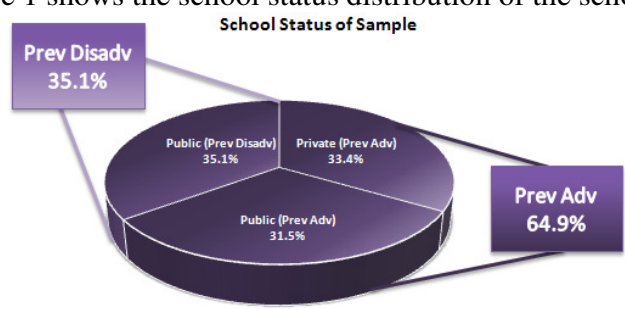

Figure 1: School Status of Sample

As Figure 1 depicts, the majority of learners in the research sample (64.9\%) come from previously advantaged schools in the Grahamstown region. A potentially inaccurate representation of all schools in the Eastern Cape is thus implied.
Four hundred questionnaires were distributed between the 11 schools, but only 308 were returned, attributable mainly to a lack of administration within the schools.

\section{FINDINGS AND ANALYSIS}

\subsection{Racial Grouping, Gender, Digital Divide}

The responses for questions relating to racial grouping, gender and access to computers and the Internet were collected and chi-squared $\left(\mathrm{x}^{2}\right)$ tests were performed to test association with interest to study CS/IS. In order to ensure adequate sub-sample sizes with comparative tests, interest in CS/IS was also combined as relative interest in "IT".

Figures 2 and 3 below show all the learners in the research sample who have an interest in IS and CS respectively, in relation to their demographic details and their access to computers and the Internet. The percentages are representative of the entire research sample (308). Fourteen percent of all the learners show an interest in IS, while twenty-five percent of all the learners show an interest in CS.

The respective $\mathrm{x}^{2}$ analysis of these results is shown in Table 1. Significant findings are in bold and these results are discussed below.

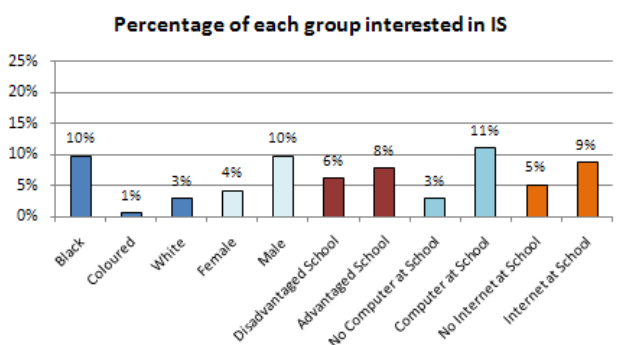

Figure 2: Percentage of each group interested in IS

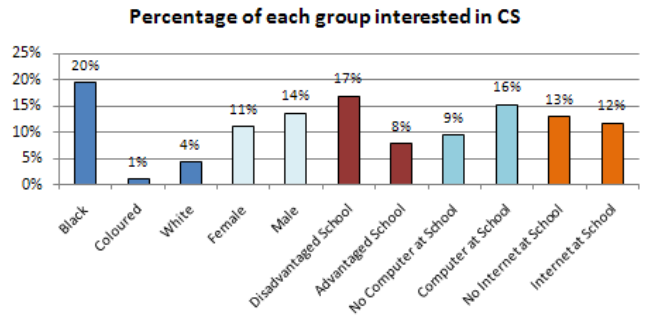

Figure 3: Percentage of each group interested in

CS

Table 1: Results of the Chi-Square Hypothesis Testing for interest in CS, IS and IT

\begin{tabular}{|c|c|c|c|c|c|c|}
\hline \multicolumn{2}{|c|}{ Hypothesis } & IS & CS & IT (CS\&IS) & Reject HO & Comment \\
\hline $\mathrm{H}_{1}$ & School Status & $\begin{array}{c}1.7789 \\
(0.1822)\end{array}$ & $\begin{array}{c}48.9454 \\
(0.000000)\end{array}$ & $\begin{array}{c}30.7696 \\
(0.00000)\end{array}$ & Yes & Only for interest in CS and IT \\
\hline $\mathrm{H}_{2}$ & \multirow{2}{*}{ Digital Divide } & $\begin{array}{l}10.1596 \\
(0.0708)\end{array}$ & $\begin{array}{c}5.8052 \\
(0.3256)\end{array}$ & $\begin{array}{c}5.0695 \\
(0.4074)\end{array}$ & No & No significance \\
\hline $\mathrm{H}_{3}$ & & $\begin{array}{c}1.1327 \\
(0.2872)\end{array}$ & $\begin{array}{c}23.8685 \\
(0.000001)\end{array}$ & $\begin{array}{c}18.8885 \\
(0.000014)\end{array}$ & Yes & Only for interest in CS and IT \\
\hline $\mathrm{H}_{6}$ & Racial Grouping & $\begin{array}{c}5.3894 \\
(0.1454)\end{array}$ & $\begin{array}{l}20.9145 \\
(0.0001)\end{array}$ & $\begin{array}{c}17.8722 \\
(0.00046)\end{array}$ & Yes & Only for interest in CS and IT \\
\hline $\mathrm{H}_{7}$ & Gender & $\begin{array}{c}8.4885 \\
(0.0035)\end{array}$ & $\begin{array}{c}1.4985 \\
(0.2209)\end{array}$ & $\begin{array}{c}5.7812 \\
(0.0162)\end{array}$ & Yes & Only for interest in IS \\
\hline
\end{tabular}


The above results indicate that:

- $\quad \mathbf{H}_{1}$ : Learners attending previously disadvantaged schools are more inclined to study CS (with no significant inclination toward IS) than those attending previously advantaged schools.

- $\quad \mathbf{H}_{2}$ : No significance to suggest an inclination toward IS or CS for learners with no access to computers at school.

- $\quad \mathbf{H}_{3}$ : Learners with no access to the Internet at school are more inclined to study CS (with no significant inclination toward IS) than those with access to the Internet at school.

- $\quad \mathbf{H}_{\mathbf{6}}$ : Black learners are more inclined to study CS (with no significant inclination toward IS) than White learners.

- $\quad \mathbf{H}_{7}$ : Female learners are less inclined to study IS (with no significant inclination toward CS) than male learners.

\subsection{Perceptions of the IT Job Market}

Figure 4 shows responses relating to learners' perceptions of the IT job market measured on a 5-point Likert-scale while Table 2 shows the results of Correlation testing on this set of variables.

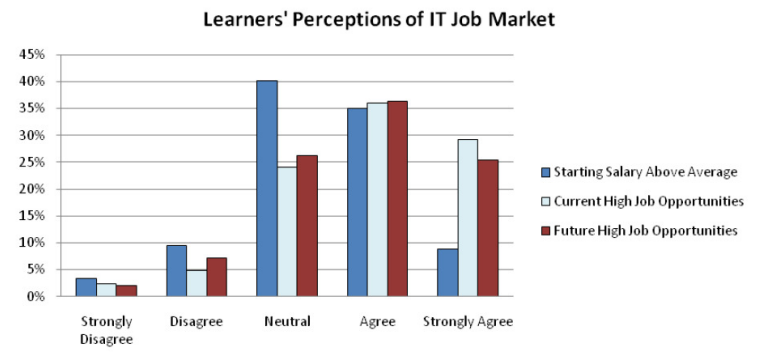

Figure 4: Learners' perceptions of IT Job Market

Table 2: Results of the Correlation Hypothesis Testing of IT Career Knowledge

\begin{tabular}{|c|c|c|c|c|c|c|}
\hline \multicolumn{2}{|c|}{ Hypothesis } & IS & CS & $\begin{array}{c}\text { IT } \\
\text { (CS\&IS) }\end{array}$ & $\begin{array}{l}\text { Reject } \\
\text { HO }\end{array}$ & Comment \\
\hline $\mathrm{H}_{8 \mathrm{~A}}$ & \multirow{3}{*}{$\begin{array}{l}\text { IT Career } \\
\text { Knowledge }\end{array}$} & $\begin{array}{l}0.1374 \\
(0.018)\end{array}$ & $\begin{array}{l}0.0555 \\
(0.342) \\
\end{array}$ & $\begin{array}{l}0.0875 \\
(0.134) \\
\end{array}$ & Yes & Only for interest in IS \\
\hline $\mathrm{H}_{8 \mathrm{~B}}$ & & $\begin{array}{l}0.0922 \\
(0.114)\end{array}$ & $\begin{array}{l}0.0744 \\
(0.202)\end{array}$ & $\begin{array}{l}0.1265 \\
(0.030)\end{array}$ & Yes & Only for combined interest in IT \\
\hline $\mathrm{H}_{8 \mathrm{C}}$ & & $\begin{array}{l}0.1013 \\
(0.083)\end{array}$ & $\begin{array}{c}0.0422 \\
(0.47)\end{array}$ & $\begin{array}{l}0.1116 \\
(0.056)\end{array}$ & No & No significance \\
\hline
\end{tabular}

As seen in Figure 4, learners have either neutral or relatively positive perceptions of the IT job market. Table 2 shows that significance is found for those learners with interest in IS who suspect that IT professionals have a starting salary above the average. With regards to current high job opportunities, while significance is not found with interest in IS and CS alone, it exists in the combination of the two as IT as a result of the increase in the sample size. The above results indicate that:

- $\quad \mathbf{H}_{\mathbf{8 A}}$ : Learners who have negative perceptions about an IT starting salary are less inclined to study IS (with no significant inclination toward CS) than those who have positive perceptions.

- $\quad \mathbf{H}_{\mathbf{8 B}}$ : Learners who have negative perceptions about the number of IT jobs currently available are less inclined to study IS or CS than those who have positive perceptions.

- $\quad \mathbf{H}_{\mathbf{8 C}}$ : No significance to suggest an inclination toward IS or CS for learners who have negative perceptions about the number of IT jobs available in the future.

\subsection{Perceptions of Typical CS/IS Students}

The mean responses for questions relating to learner perceptions of typical CS/IS students and the academic perceptions of the same set of statements are given in Table 3. Learners' responses are compared to academics' responses to determine how correct learners' perceptions of CS and IS are. Significant differences are indicated in bold and discussed below.

Learners appear to have relatively inaccurate perceptions of what typical CS students spend most of their time doing, while their perceptions of typical IS students differ significantly from those held by academics. Therefore:

- $\quad \mathbf{H}_{9}$ : Learners do not know what IS as a field of study entails.

- $\quad \mathbf{H}_{\mathbf{1 0}}$ : Learners do not know what CS as a field of study entails (to a lesser extent).

\section{COMPARISON OF FINDINGS WITH SEYMOUR ET AL. (2005) [20]}

Even though a number of factors affect students' inclinations to study an IT-related degree at tertiary level, this study considered the effect that demographics and access to technology have on South African Grade 12 learners. The results from the empirical study conducted in Grahamstown and the comparison to related work in the Western Cape by Seymour et al. [20] are presented below:

Interestingly, despite the difference in location and time between the two studies, both show very similar results with regard to learners' inclinations to study IS and CS. 
Table 3: Results of the T-Hypothesis Testing for Perceptions of Typical IS and CS Students

\begin{tabular}{|c|c|c|c|c|}
\hline An IS Student & Learner Mean & Academic Mean & $\mathbf{t}$ & $\mathbf{P}$ \\
\hline 10. Writing programs & 3.286 & 2.059 & 4.987 & $(0.000001)$ \\
\hline 11. Interacting people & 2.916 & 4.000 & -4.353 & $(0.000018)$ \\
\hline 12. Working alone & 3.165 & 1.941 & 4.766 & $(0.000003)$ \\
\hline 13. Designing $\mathrm{H} / \mathrm{Ware}$ & 3.203 & 1.059 & 7.775 & $(0.000000)$ \\
\hline 14. Whiz at Maths & 3.099 & 1.471 & 6.182 & $(0.000000)$ \\
\hline 15. Strong prior background & 3.341 & 1.882 & 4.903 & $(0.000002)$ \\
\hline \multicolumn{5}{|l|}{ A CS Student } \\
\hline 16. Writing programs & 3.492 & 4.056 & -2.198 & $(0.028639)$ \\
\hline 17. Interacting people & 3.007 & 2.556 & 1.978 & $(0.048826)$ \\
\hline 18. Working alone & 3.172 & 2.944 & 0.919 & $(0.358599)$ \\
\hline 19. Designing $\mathrm{H} / \mathrm{Ware}$ & 3.169 & 2.500 & 2.572 & $(0.010570)$ \\
\hline 20. Whiz at Maths & 3.404 & 3.056 & 1.293 & $(0.196851)$ \\
\hline 21. Strong prior background & 3.495 & 3.278 & 0.760 & $(0.447577)$ \\
\hline
\end{tabular}

- $\quad \mathbf{H}_{1}$ : Seymour [20]: Learners attending previously disadvantaged schools are more inclined to study IS or CS than those attending previously advantaged schools. This Study: Learners attending previously disadvantaged schools are more inclined to study CS (with no significant inclination toward IS) than those attending previously advantaged schools.

- $\quad \mathbf{H}_{2}$ :Seymour [20]: Learners with no access to computers at school are more inclined to study CS (with no significant inclination toward IS) than those with access to computers at school.

This Study: No significance to suggest an inclination toward IS or CS for learners with no access to computers at school.

- $\mathbf{H}_{3}$ : Seymour [20]: Learners with no access to the Internet at school are more inclined to study IS or CS than those with access to the Internet at school. This study: Learners with no access to the Internet at school are more inclined to study CS (with no significant inclination toward IS) than those with access to the Internet at school.

- $\mathbf{H}_{\mathbf{6}}$ : Both Seymour [20] and this study: Black learners are more inclined to study CS (with no significant inclination toward IS) than White learners.

- $\quad \mathbf{H}_{7}$ : Both Seymour [20] and this study: Female learners are less inclined to study IS (with no significant inclination toward CS) than male learners.

- $\mathbf{H}_{\mathbf{8 A}}$ : Seymour [20]: No significance to suggest an inclination toward IS or CS for learners with negative perceptions about an IT starting salary.

This study: Learners who have negative perceptions about an IT starting salary are less inclined to study IS (with no significant inclination toward CS) than those who have positive perceptions.

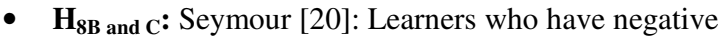
perceptions about the number of IT jobs available in the present and future are less inclined to study IS or CS than those who have positive perceptions.
This Study: Learners who have negative perceptions about the number of IT jobs currently available are less inclined to study IS or CS than those who have positive perceptions.

- $\quad \mathbf{H}_{9}$ and 10: Both Seymour [20] and this study: Learners do not know what IS as a field of study entails, but have more accurate perceptions about what CS as a field of study entails.

The study thus shows that the significant factors that influence learners in their attitudes toward further degrees in IT remain school status, the digital divide, racial grouping, gender and IT job market perceptions. Previously disadvantaged learners and those with no access to the Internet at school are more inclined to study CS. Black learners are also more inclined to study CS than white learners. Female learners are less inclined to study IS. Finally, learners with negative perceptions about the IT job market are less inclined to study either CS or IS.

\section{FURTHER ANALYSIS AND LIMITATIONS}

The Eastern Cape houses over 6000 schools, a very small percentage of which have access to computers and the Internet, in comparison with other provinces in South Africa. The study collected data from the small geographical surroundings of Grahamstown. The Eastern Cape is considered the most rural of provinces in terms of educational facilities and resources. Grahamstown, however, boasts some of the most respected and prized previously advantaged schools in the country. Even though $35 \%$ of the respondents came from previously disadvantaged schools, a significant $65 \%$ did not. Future research is recommended in choosing a learner sample from the greater region covering a diverse range of previously advantaged and disadvantaged schools where the effects of the digital divide can be more accurately noted.

In addition, while this research analyses the perceptions and inclinations of learners toward IT-related degrees, it may 
be useful to determine how tertiary institutions can best enhance the marketing strategies of their IT subjects by engaging with secondary institutions. Learners' perceptions about subject choices will thus be "de-mystified" and their interest will develop from an earlier age.

\section{CONCLUSION}

The research analysed determinants behind the ICT skills shortage by focusing on the generation of individuals that are yet to enter tertiary education. By analysing interest levels and inclinations toward IT degrees from the perspectives of Grade 12 learners, this research established that the reasons behind the decline in IT enrolments in South Africa is influenced by an underlying demographic and digital divide.

Unlike previous research, the fact that certain groups of people (previously disadvantaged and females) have not had exposure to computers or the Internet, coincides with an increased interest to study IT-related subjects. The strong inclination to overcome this digital divide seems to have removed some of the myths of computer self-efficacy and anxiety. On the other hand, those with exposure to technology have a decreased interest in pursuing IT-related degrees, which could be classified as a direct result of technology's increased integration into our daily lives and its stance as a commodity akin to electricity and the like.

An underlying responsibility is placed on educational institutions to promote accurate representations of the IT-related subjects on offer. An increasing number of students have preconceived ideas about the subjects that severely misrepresent their real nature and outcomes. Educational institutions need to be aware of this in order to create a marketing strategy that will address the misconceptions about the IT-related subjects on offer and provide prospective students with exciting and innovative endeavours that will increase their awareness of the subjects and thus their inclinations to enrol for them.

\section{REFERENCES}

[1] ACM. (2001). Computing Curricula 2001 Computer Science. CC2001 Computer Science Volume Final Report (pp. 1-236). National Science Foundation.

[2] Arora, S., \& Chazelle, B. (2005). Is the Thrill Gone? Comm ACM , 31-33.

[3] Birchwood Declaration. (March, 2007). Tertiary Level ICT Skills Development. Colloquium on Information and Communication Technology Education and Training and the Production of Graduates, (pp. 1-5). Johannesburg.

[4] Burger, A., \& Blignaut, P. (2004). A Computer Literacy Course may Initially be Detrimental to Students' Attitudes towards Computers. SAICSIT , 10-14.

[5] Cale, E., Mawhinney, C., \& Callaghan, D. (1991). Implications of Declining Enrolments in Undergraduate CIS Programs in the United States. Management Information Systems , 167-181.

[6] CNET. (2005). College freshmen less interested in tech. Retrieved February 17, 2008, from NEWS.COM: http://www.news.com/College-freshmen-less-interestedin-tech/2100-1022 3-5681438.html.

[7] Denning, P., \& McGettrick, A. (2005). Recentering Computer Science. Comm ACM , 15-19.
[8] Denny, P. (2008). ICT Skills Shortage Set to Worsen. Retrieved March 5, 2008, from IT-Online: http://itonline.co.za/content/view/222848/129/

[9] Department-of-Education. (2008a). National Curriculum Statement - Learning Programme Guidelines - Computer Applications Technology. Retrieved May 15, 2008, from http://www.education.gov.za/Curriculum/LPGs2007/LP G\%20COMPUTER\%20APPLICATIONS\%20TECHNO LOGY.pdf

[10] Department-of-Education. (2008b). National Curriculum Statement - Learning Programme Guidelines - Information Technology. Retrieved May 15, 2008, from http://www.education.gov.za/Curriculum/LPGs2007/LP G\%20INFORMATION\%20TECHNOLOGY.pdf

[11] Frauenheim. (2004). Computer Science Turns Off Students. Retrieved February 15, 2008, from ZDNET: http://news.zdnet.co.uk/itmanagement/0,1000000308,39 163263,00.htm.

[12] Granger, M., Dick, G., Jacobson, C., \& van Slyke, C. (2007). Information Systems Enrollments: Challenges and Strategies. JISE , 303-314.

[13] Klawe, M. (2005). Changing the Image of Computer Science: A North American Perspective in Conversation with Europe. Comm ACM , 3.

[14] Klawe, M., \& Schneiderman, B. (2005). Crisis and Opportunity in Computer Science. Comm ACM , 27-28.

[15] McBride, N. (2007). The Death of Computing. Retrieved February 14, 2008, from http://www.bcs.org/server.php?show=ConWebDoc.9662

[16] Moleke, P., Paterson, A., \& Roodt, J. (2003). ICT and Associated Professionals. HSRC, 634-659.

[17] Paterson, A. (March, 2007). ICT Skills in South Africa. Birchwood Declaration: Colloquium on Information and Communication Technology Education and Training and the Production of Graduates, (pp. 121). Johannesburg.

[18] Patterson, D. (2005). Restoring the Popularity of Computer Science. Comm ACM , 25-28.

[19] Roddick, J., \& Nieuwenhuis, A. (2001). Application Rates to Undergraduate Programs in Information Technology in Australian Universitities. ACSC, 223-231.

[20] Seymour, L., Hart, M., Haralambous, P., Natha, T., \& Weng, C. (2005). Inclination of Scholars to Major in Information Systems or Computer Science. SACJ , 97106.

[21] Short, M., \& Fischer, C. (2008, May 13). Rhodes CS and IS Enrolment Figures. (C. Jacobs, Interviewer)

[22] Slonim, J., Scully, S., \& McAllister, M. (2008). Outlook on Enrolments in Computer Science in Canadian Universities. ICTC , 1-44.

[23] Stewart, J., \& Balgenorth, B. (2007). The Importance of Technology Education. Retrieved February 25, 2008, from TECHINTHECLASS: http://techintheclass.blogspot.com/2007/11/importanceof-technology-education.html. 